\title{
Making the Black Box of Collaborative Learning Transparent: Combining Process-Oriented and Cognitive Load Approaches
}

\author{
Jeroen Janssen • Femke Kirschner • Gijsbert Erkens • \\ Paul A. Kirschner • Fred Paas
}

Published online: 4 May 2010

(C) The Author(s) 2010. This article is published with open access at Springerlink.com

\begin{abstract}
Traditional research on collaborative learning employs a "black box" approach that makes it difficult to gain a deeper understanding of the differential effects of collaborative learning. To make the black box transparent, researchers have studied the process of collaboration, in order to establish which interaction features are likely to make learning more effective and efficient for group members. Although cognitive load theory has been developed in the context of individual learning situations, it may provide a promising new way of looking inside the black box, assuming that students working in groups have more processing capacity than students working individually. The aim of this article is to provide an overview of the process-oriented and cognitive-load approaches to conducting collaborative learning research, to highlight their respective advantages and disadvantages, and to suggest how they can be combined in order to address new research questions.
\end{abstract}

Keywords Collaborative learning · Cognitive load theory · Process-oriented research · Group member interaction $\cdot$ Cognitive load measurement

J. Janssen $(\bowtie) \cdot$ G. Erkens

Research Centre Learning in Interaction, Utrecht University, P.O. Box 80140, 3508 TC, Utrecht, The Netherlands

e-mail: J.J.H.M.Janssen@uu.nl

G. Erkens

e-mail: G.Erkens@uu.nl

F. Kirschner $\cdot$ F. Paas

Institute of Psychology, Erasmus University Rotterdam, P.O. Box 1738, 3000 DR, Rotterdam,

The Netherlands

F. Kirschner

e-mail: kirschner@fsw.eur.nl

F. Paas

e-mail: paas@fsw.eur.nl

P. A. Kirschner $\cdot$ F. Paas

Centre for Learning Sciences and Technologies, Open University of The Netherlands,

P.O. Box 2960, 6401 DL, Heerlen, The Netherlands 
What more is there to be learned from researching collaborative learning? In a recent article, "the widespread and increasing use" of collaborative learning has been called a "success story" (Johnson and Johnson 2009, p. 365). In this article, we describe several different perspectives on collaborative learning research. Our main goal is to argue that combining new insights and methods derived from cognitive load theory (CLT; i.e., considering groups as information processing systems that have more processing capacity than individual learners) with process-oriented research (i.e., studying the processes that occur between learners during collaboration) provides a new and promising direction for collaborative learning research, which can shed more light on the processes that may or may not contribute to the effectiveness of collaborative learning.

Collaborative learning can be defined as a learning situation during which students actively contribute to the attainment of a mutual learning goal and try to share the effort to reach this goal (Teasley and Roschelle 1993). Although, on the short run, this would result in group members trying to successfully perform a certain task or solve a specific problem together, on the long run, it is very important that every group member also learned something from this combined effort. Although often a distinction is made between collaborative and cooperative learning, usually associating cooperative learning with division of labor among group members and collaborative learning with a continuous mutual effort of group members to learn by solving problems together (Paulus 2005; Roschelle and Teasley 1995), there are several important similarities between collaborative and cooperative learning (for example, in both cases, learners participate in small-group learning activities and are made responsible for their learning process; see Kreijns et al. 2003). For the sake of clarity, we therefore use the term collaborative learning throughout this paper.

Another important similarity between collaborative and cooperative learning concerns the theories that can be called upon to explain the benefits of small-group learning activities for learning. Aspects of several distinct theories, developed in different disciplines (e.g., social psychology and developmental psychology), can be called upon to explain why students can - under the right circumstances - learn from interaction and discussion with their peers. Social psychology stresses the beneficial effects of the social cohesion that is created by the act of working interdependently on a group task (O'Donnell and O'Kelly 1994). Social cohesion strengthens group members' desire to help one another and to contribute equally to the group task. Cognitive developmental theories, based, for example, on the work of Vygotsky and Piaget, highlight the importance of learning mechanisms during collaboration that promote development of new cognitive schemas (Fawcett and Garton 2005). Vygotsky's (1978) concept of the zone of proximal development is often used to explain that collaborative learning is beneficial for learners because the more capable learner can help and scaffold, the less capable learner to accomplish a task he or she could not accomplish while working individually.

The study of collaborative learning thus has a long and rich tradition, which has led to the publication of a vast number of research studies examining the effects of collaborative learning on a range of dependent variables, such as student achievement (e.g., Nichols 1996), time on task (e.g., Klein and Pridemore 1992), motivation (e.g., Jones and Issroff 2005), and use of metacognitive strategies (e.g., Mevarech and Kramarski 2003). This line of research has become known as effect-oriented research (Dillenbourg et al. 1996; Van der Linden et al. 2000). In their review, Johnson and Johnson (2009) identified over 1,200 studies comparing the relative effects of collaborative learning to, for example, individual learning. It can therefore be concluded that effect-oriented research has a strong research tradition in this field. Unsurprisingly, this overwhelming amount of research fuelled a need 
for research synthesis. Several meta-analyses have thus been carried out showing that collaborative learning can be an effective strategy for promoting retention and problem solving (e.g., Lou et al. 2001; Roseth et al. 2008; Slavin 1980; Springer et al. 1999). It must be noted, however, that not all studies have found positive effects for collaboration (e.g., Andersson and Rönnberg 1995; Kirschner et al. 2009c; Meudell et al. 1992).

Notwithstanding this impressive body of research, several authors have criticized effectoriented research, claiming that it employs a black box approach that makes it difficult to explain the variability in research findings (Cohen 1994; Dillenbourg 1999; Pelled et al. 1999). How can we, for example, explain why not all groups function well and foster the learning process of individual students (cf., O'Donnell and O'Kelly 1994; Salomon and Globerson 1989)? Because effect-oriented research does not focus on the intervening variables that may affect the learning outcome of collaborative learning, other research approaches are necessary to understand why in some cases groups do not always collaborate effectively (e.g., Barron 2003) and why students' understanding of the learning material sometimes even deteriorates during collaboration (e.g., Tudge 1989). In the remainder of this article, we will therefore explore process-oriented research (i.e., research focusing on the process of collaboration rather than the effect of collaboration) and research based on the cognitive load theory (CLT; i.e., research focusing on the measurement of cognitive load and performance to gain insight into the quality of constructed cognitive schemas), as complementary research traditions alongside effect-oriented research in order to gain a more complete understanding of collaborative learning.

Although many theories on collaborative learning explain the benefits of collaborative learning by referring to the interaction processes taking place between group members (O'Donnell and O'Kelly 1994; Slavin 1996), the interaction process itself is not studied in effect-oriented research. A deeper understanding of the underlying mechanisms of collaborative learning is, however, necessary to understand the complex relationships and interactions between task, learner, and group characteristics. These characteristics, however, often interact (e.g., the effect of group members' prior knowledge on their achievement during collaborative learning may depend on whether they collaborate in homogeneous or heterogeneous groups). It is therefore difficult to establish direct relationships between these characteristics and the learning effect of collaboration. This creates the necessity to study the interactions between students during collaboration and to establish how task, learner, and group characteristics affect student interactions and how these interactions in turn affect students' learning process (Dillenbourg et al. 1996).

\section{Process-Oriented Collaborative Learning Research: Advantages and Disadvantages}

Impressive, though, the findings from the effect-oriented tradition may be, these studies have been criticized because they treat collaborative learning as a black box by comparing collaborative learning to another learning situation solely on outcome measures (Bossert 1988; Cohen 1994; Dillenbourg 1999). This is problematic because such an approach does not explain why in some groups the interaction between group members contains high levels of reasoning and collective thinking resulting in learning gains for all students, while in other groups - although they were assigned the same task-the quality of group members' interaction and learning is disappointing (Barron 2003; Hogan et al. 1999; Webb et al. 2002). A possible explanation is that these results might be due to factors such as group composition and students' prior knowledge and social skills. More likely, this is probably due to the complex interactions between features of the task, student, and group 
(Dillenbourg et al. 1996; Kirschner et al. 2009a; Webb and Palincsar 1996). Although a number of effect-oriented studies focused on context factors such as group composition, they neither study nor explain the mechanisms behind the effects of these factors.

Several researchers have tried to address the black box issue by studying the process of collaboration, attempting to establish which interaction features are likely to generate favorable learning results for group members. Studies in this so-called process-oriented tradition (Dillenbourg et al. 1996; Van der Linden et al. 2000) focus on interaction processes such as giving detailed, elaborated explanations (Webb and Farivar 1999), negotiating meaning (Beers et al. 2007), co-constructing solutions and lines of reasoning (Van Boxtel et al. 2000), and developing and formulating arguments during collaboration (Janssen et al. 2010; Kuhn and Udell 2003).

Although an extensive discussion of process-oriented is beyond the scope of this article, we will to illustrate the advantage of this approach by highlighting two examples. The first example concerns studies that focus on the process of giving and receiving explanations that occurs during collaborative learning. This process has been extensively studied by Webb and her colleagues (cf., Webb 1989; Webb and Farivar 1999; Webb and Mastergeorge 2003; Webb et al. 2002; Webb et al. 1995). This line of research demonstrated that giving elaborate explanations (i.e., an explanation that contains a reason why the problem should be solved in a certain way) correlates positively with student achievement, whereas giving explanations without an elaboration (i.e., telling someone the answer without giving a clarification) does not (Webb 1991).

Furthermore, the relationship between receiving explanations and learning is not straightforward. Although receiving an explanation not containing an elaboration or receiving no explanation at all is negatively correlated with learning (Webb 1989; Webb and Farivar 1999), additional conditions have to be met in order for elaborate explanations to be effective for the receiver. Studies by Webb and Farivar (1999), Webb et al. (1995), and Webb and Mastergeorge (2003), for example, showed that elaborate explanations were only effective when the receiver was able to apply the explanation in a related task.

The research on giving and receiving explanations during collaborative learning focuses not only on the relationship between these processes, group performance, and student achievement but also on the conditions under which these processes are more likely to occur. Group-ability composition, for example, affects the accuracy and quality of explanations during the collaborative process. Research has demonstrated that it is important that a certain level of expertise is available within the group, because the quality of explanations is higher in groups with above-average students than in groups without these students (Webb et al. 1998). The work done by Webb shows how systematically studying aspects of the collaborative process can lead to more insight into the conditions under which optimal group processes unfold and how these processes affect students' learning processes.

Whereas the research on giving and receiving explanations uses the individual as the unit of analysis, other process-oriented studies focus on the group as the unit of analysis (Dillenbourg et al. 1996). Barron (2003), for example, studied the differences between successful and less successful groups in terms of group performance. She found marked differences between these groups with respect to how group members responded to proposals by group members and how well they were able to maintain joint attention. The more successful groups reacted more appropriately or with a higher level of engagement to correct proposals offered by a group member. Appropriate or engaged responses are, for example, acceptations of the proposal or starting a constructive discussion. Inappropriate responses are ignoring the other and/or the proposal or outright rejections of the proposal 
without discussion. Successful groups display higher levels of these engaged responses compared with unsuccessful groups. Furthermore, members of successful groups were better at maintaining joint attention because their contributions were more often in line with previous discussion. Barron also showed that the group members of successful groups outperformed members of less successful groups on individual mastery and transfer tests. Thus, in this case, too, process-oriented research led to a better understanding of how collaborative processes such as responding appropriately and maintaining joint attention contribute to group performance and student achievement.

Studies like the one done by Barron have highlighted the importance of interindividual coordination and regulation during collaborative learning (see also Erkens et al. 2005; Van der Meijden and Veenman 2005). Metacognitive activities that regulate task performance (e.g., making plans, monitoring task progress, and evaluating plans or ideas) are, for example, considered important to successful performance during collaboration (Artzt and Armour-Thomas 1997; De Jong et al. 2005; Janssen et al. 2007; Slof et al. in press). Also, collaboration requires coordination or regulation of collaborative activities. During successful collaboration, group members are interdependent, and therefore, they have to discuss collaboration strategies, monitor collaboration processes, and evaluate and reflect on the manner in which they collaborated (Janssen et al. 2007; Phielix et al. 2010). Although interindividual coordinative and regulative activities are thus important for effective collaboration, it could, however, also be argued that these activities detract group members from engaging in task-related learning activities and therefore dampen the positive effects of collaborative learning on group members' learning (F. Kirschner et al. 2009a; 2009b; 2009c).

Although the work done by Webb, Barron, and others clearly shows the strengths of process-oriented collaborative learning research, a sole focus on the interaction process can have drawbacks as well. In process-oriented research, there seems to be a tendency to zoom in on several features of the interaction process (cf., Elbers and Streefland 2000; Kumpulainen et al. 2001; Yackel et al. 1991) without systematically considering at the same time how these interaction patterns came about (e.g., examining the differential effects of homogeneous or heterogeneous ability grouping on group processes) or how they affect group performance and individual learning gains (F. Kirschner et al. 2009a, c). Such an approach can give rich and detailed descriptions about the mechanisms of collaboration or can be used to generate testable hypotheses. It does not explain, however, how these mechanisms developed within the group, nor does it give insight into how they affected group performance and student learning. To gain a more fundamental understanding about collaborative learning, it is important to study both the antecedents and consequences of the collaborative process (Stodolsky 1984).

\section{Applying Cognitive Load Theory to Collaborative Learning: Advantages and Disadvantages}

In trying to unravel the complex interplay between task, learner, and group characteristics in collaborative learning environments, it is important to study not only the effects of collaborative learning (i.e., the effect-oriented approach) or the processes that occur between learners (i.e., the process-oriented approach) but also the processes that occur within each learner's head. Taking the structures that constitute human cognitive architecture into account will provide more insight in and understanding about the conditions under which collaborative learning is (most) effective and efficient. 
Cognitive load theory (CLT: Paas et al. 2003a; Paas et al. 2004; Sweller 2010, this issue; Sweller et al. 1998; Van Merriënboer and Sweller 2005), a theoretical framework grounded in the learner's cognitive architecture, has shown that learning environments for complex cognitive tasks can only be effective and efficient when they are designed in such a way that they facilitate changes in learners' long-term memory (LTM) associated with schema construction and schema automation (i.e., learning). In this context, the limited processing capacity of a learner's working memory (WM) is considered a bottleneck (Baddeley 1986; Miller 1956); for new, yet to be learned information, its processing capacity is limited to only $4 \pm 1$ elements (Cowan 2010), and if a learning environment is too cognitively demanding, schema construction and schema automation in LTM are not going to occur (P.A. Kirschner et al. 2006). Therefore, in trying to better understand the effectiveness and efficiency of collaborative learning, it is essential that the cognitive load imposed on a group member's WM be taken into account (Paas et al. 2003b; Paas and Van Merriënboer 1993; Van Gog and Paas 2008).

Information processing in collaborative learning settings is characterized by active and conscious sharing (i.e., retrieving and explicating information), discussing (i.e., encoding and elaborating the information), and remembering (i.e., personalizing and storing the information) of valuable task-relevant information and knowledge held by each group member (Hinsz et al. 1997; Tindale and Kameda 2000; Tindale and Sheffey 2002). According to the evolutionary perspective of CLT on human cognitive architecture, humans have evolved to communicate with each other and obtain most of their information from each other. This led to the borrowing and reorganizing principle (Sweller 2004; Sweller and Sweller 2006), which states that LTM is built primarily by imitating other people, through the borrowing of information from other people's LTM. This process involves constructive reorganization in that new information must be combined with previous information using a constructive process. The principle suggests that information can be better obtained from an instructor, either in person or via instructional materials, than by discovering information oneself, although it does not mean that information is directly copied from one person to the other without any alteration.

Most research demonstrating the principle is based on individual learning environments (Hasler et al. 2007; Paas 1992; Van Gog et al. 2009b). However, the borrowing and reorganizing principle applies to any information obtained from another human. Collaborative learning environments are therefore an ideal example of the principle at work. Humans collaborate in large part because the people they are collaborating with can provide them with information more efficiently under many circumstances, than if they must obtain that information without assistance from others. For a group to carry out a learning task, not all group members need to possess all necessary knowledge, or process all available information alone and at the same time (Johnson et al. 1989; Langfred 2000; Ortiz et al. 1996; Wegner 1987, 1995). As long as there is communication and coordination between the group members, the information elements within the task and the associated cognitive load caused by the intrinsic nature of the task (i.e., intrinsic cognitive load) can be divided across a larger reservoir of cognitive capacity.

This view of collaborative learners as information processing systems (Hinsz et al. 1997; Kirschner et al. 2009a; 2009c) in which the information necessary for carrying out a learning task and its associated cognitive load can be divided across multiple collaborating WMs has two consequences. On the one hand, this distribution advantage causes collaborating individuals to invest less cognitive effort when carrying out the learning task as compared with individuals learning alone (i.e., collaborating learners experience less intrinsic cognitive load). On the other hand, the interindividual communication and coordination of information requires group members to invest 
additional cognitive effort, an effort that individuals learning alone do not have to exert. These so-called transaction costs (Ciborra and Olson 1988; Yamane 1996) can be effective (i.e., imposing a germane cognitive load) or ineffective (i.e., imposing an extraneous cognitive load) for learning. In the former case, this means that the imposed cognitive load fosters shared understanding, trust, mutual performance monitoring, common ground, argumentation, coordination, or positive cognitive conflicts (Leitão 2000; Mercer 1996; Munneke et al. 2007; Salas et al. 2005; Savery and Duffy 1995). In the latter case, the imposed cognitive load fosters errors, conflicts, unnecessary duplication, and so on (Bernard and Lundgren Cayrol 2001; Webb and Palincsar 1996). Whether collaboration will be more effective than individual instruction for students' learning will therefore depend on whether the distribution advantage is large enough to compensate for the extraneous transaction costs.

Which kind of cognitive load the transaction costs impose on a group member, and consequently how effective it will be for this students' learning, depends on the interplay between task characteristics, learner characteristics, and group characteristics. This interplay causes the effectiveness of collaborative learning environments to differ between groups as well as within groups. For example, if a learner has sufficient expertise to carry out a complex collaborative task alone, the communication and coordination processes will not be necessary for learning or may even interfere with learning because it imposes ineffective (i.e., extraneous) cognitive load. In contrast, when a learner in that same group needs other learners for the collaborative task to be carried out successfully, the communication and coordination processes are necessary for learning and can facilitate learning (i.e., giving elaborate explanations; Webb 1991), imposing effective (i.e., germane) cognitive load. The trade-off between the expansion of cognitive capacity caused by the possibility to divide information processing among group members and the associated cognitive costs of interindividual communication and coordination of information is an important aspect determining under which conditions collaborative learning environments may or may not be effective for learning.

Furthermore, CLT provides the opportunity to study and measure the consequences of the collaborative learning process in terms of a learner's schema construction and schema automation. While effect-oriented research merely uses outcome performance (e.g., number of correctly answered assessment items, time on task, and quality of the product) as an indication of learning, Paas and Van Merriënboer (1993; see also Paas et al. 2003b) have shown that a performance score can only be meaningfully interpreted in the context of the level of cognitive load that it induces and vice versa. For instance, a performance score on a test does not provide information about the cognitive costs at which this performance was attained. Therefore, taking both performance and cognitive load on a test into account gives a better indication of the quality of the cognitive schemas participants have acquired than do performance scores alone, since showing less cognitive load with an equal or higher performance is an indicator of the availability of higher-quality cognitive schemas. This insight has led Paas and Van Merriënboer (1993; see also Tuovinen and Paas 2004; Van Gog and Paas 2008) to develop a computational approach for examining the observed relation between measures of test performance and measures of mental effort invested in completing the test. This approach enables cognitive load theorists and instructional designers to calculate and compare the efficiency of instructional conditions: high task performance associated with low mental effort is termed high performance efficiency, whereas low task performance with high mental effort is termed low performance efficiency. The value of the approach has been shown by revealing differential effects of varying instructional methods that would have gone unnoticed with conventional performance measures (like the findings from the effect-oriented tradition). 
Taking a cognitive load approach to collaborative learning can lead to a better understanding of how, when, and why collaborative learning is effective and efficient for learning. This has been demonstrated by F. Kirschner and her colleagues (2009a, b, c) in a series of studies into the differential effects of the amount of cognitive load imposed by learning tasks on both learning process and outcome efficiency of students working individually or in a group. On the basis of CLT, F. Kirschner et al. argued that one of the primary causes for the observed need to implement extra measures to ensure that group members work together (cf., P. A. Kirschner et al. 2008) was that the tasks that were presented to students in the collaborative learning setting were not demanding enough to necessitate working together. F. Kirschner et al. expected that requiring students to work together on low-complexity tasks would impede student learning or cause the students to choose to not work together. In their experiments, F. Kirschner and colleagues found that collaborating learners carrying out cognitively challenging tasks for which they, as individual learners did not have sufficient processing capacity to successfully process the information, had the advantage of being able to divide the information processing of a task among each other, thereby expanding the cognitive capacity at their disposal. Because this cognitive distribution benefit proved to be higher than the additional costs of interindividual integration and coordination of information, collaborating learners learned more effectively and efficiently than did individual learners. In contrast, with cognitively unchallenging tasks for which the individual learner had sufficient cognitive capacity to successfully carry out the task alone, the advantage at the group level of the expanded cognitive capacity disappeared. Working in a group even became disadvantageous for learning effectiveness and efficiency because group members had to be engaged in cognitive activities related to interindividual communication and coordination.

These findings are consistent with previous research on group versus individual learning which showed that group learning is superior to individual learning for relatively complex problem-solving tasks (Laughlin et al. 2002; Laughlin et al. 2006) and that individual learning is superior to group learning for relatively simple recall tasks (e.g., Andersson and Rönnberg 1995; Meudell et al. 1992; Weldon and Bellinger 1997). On the basis of these results, the challenges that a learning task poses to the cognitive capacity of the learner was identified as an important factor determining whether collaborative learning was more effective and efficient than individual learning.

Although this work clearly shows the strengths of a CLT approach of collaborative learning research, it is based on specific hypotheses regarding the possible beneficial and/or deleterious effects of interindividual communication and coordination of information (i.e., transaction costs), which were not monitored or analyzed. Because the measurement of cognitive load during learning is often an overall score and only gives an indication of its effectiveness or ineffectiveness for learning after combining it with the performance score on an individual posttest (Van Gog and Paas 2008), conclusions on the different kinds of imposed cognitive load (i.e., intrinsic, germane, and extraneous) and the associated effectiveness and efficiency of collaborative learning can only be based on a specific instruction instead of on the specific processes that occurred during the instruction such as the topics discussed, the type of discussions carried out (e.g., content related or social in nature), the role of social talk, the equality of group member participation, and the roles or patterns of communication. To gain a more fundamental understanding of collaborative learning, both the activities that occur within the heads of the learners as the activities that occur between learners should be studied at the same time. It should be noted that the same remark can be made for research using a CLT approach to study individual learning; this line of research has also neglected to study cognitive processes directly (Van Gog et al. 2009a). 


\section{Combining Process-Oriented Research and Cognitive Load Theory: Possible Directions}

In the previous paragraphs, the strengths and weaknesses of both process-oriented and cognitive load approaches for researching collaborative learning were discussed. This section will attempt to outline possible directions for collaborative learning research involving the combination of these two approaches.

\section{Providing Insight into the Collaborative Learning Process}

Process-oriented research on collaborative learning provides valuable insight into the mechanisms involved in collaboration. CLT research, on the other hand, provides valuable insight into the load imposed upon group members during collaboration and by combining this with performance measures, insight into its effect on learning, and schema construction. Both approaches, however, also have their limitations. The process-oriented approach, for example, does not consider how specific interaction patterns come about or how they affect group performance and individual learning gains. The CLT approach, in contrast, neither monitors nor analyzes the specific processes involved in interindividual communication and coordination of information (i.e., the transaction costs) and, therefore, provides no information about whether these processes are effective (i.e., imposing effective germane cognitive load) or ineffective (i.e., imposing an ineffective extraneous cognitive load) for learning. The combination of the process-oriented and the cognitive load approaches to research on collaborative learning can, therefore, provide important information on the interplay between the characteristics of the task, the learner, and the group that affect group performance and student learning.

In our opinion, the combination of approaches cancels out the disadvantages of both approaches leading to a deeper and more detailed insight into the learning through collaboration, making it possible to determine which specific aspects of the collaborative process impose either germane or extraneous cognitive load. To do this, researchers would have to examine the collaborative process to look for specific indicators of interindividual communication and coordination such as maintaining common ground, engaged response, and discussing collaboration strategies (Barron 2003; Erkens et al. 2005) and then combine them with measures of cognitive load and post-test performance and learning (Kirschner et al. 2009a). In this way, it is possible to determine which transaction costs are germane to learning and which are not. To this end, this combination allows researchers to determine:

a. the effectiveness of the communication and coordination processes for learning,

b. the extent to which the instructional format used is effective for learning, and

c. which specific processes impose effective or ineffective cognitive load and, therefore, facilitate or impede learning.

\section{Studying the Relationships Between Antecedents, Collaboration, and Consequences}

By combining process-oriented and cognitive load research, it is also possible to gain a deeper understanding of the relationships between the antecedents of collaboration (e.g., task complexity, group member composition, and prior knowledge), the collaborative process itself (e.g., carrying out the task, solving the problem, maintaining common ground, sharing information, and giving explanations), and the consequences of collaborative 
learning (e.g., group performance, study time, and student learning). When these two research traditions are thus combined, it is possible to study the whole process of collaborative learning instead of focusing on a single aspect of the process (e.g., the antecedents or the process itself). Effect-oriented research that investigates these relationships focuses on the direct relationship between, for example, group composition and students' individual performance on a posttest (see, for example, Andersson and Rönnberg 1995; Buchs and Butera 2009), whereas process-oriented research also takes the collaborative process into account (for example, Denessen et al. 2008; Webb et al. 1998). In this way, Denessen et al. were, for example able to demonstrate that medium-ability students perform better on an individual posttest when they collaborate with a low-ability student, compared with when they collaborate with a high-ability student. Furthermore, in medium-low dyads, Denessen et al. found medium-ability students to have more opportunities to give elaborate explanations.

When studies like the one conducted by Denessen et al. (2008) would also incorporate cognitive load measures (e.g., the unidimensional nine-point symmetrical mental effort rating scale [Paas 1992], heart-rate variability [Paas and Van Merriënboer 1994], taskevoked pupillary responses [Van Gerven et al. 2002], or responses to secondary tasks [Marcus et al. 1996]), it would become possible to determine how the antecedents of collaborative learning affect cognitive load and how cognitive load, in turn, affects the outcome of the collaborative process. For example, it may be the case that in medium-high dyads, students experience less germane load because they have less opportunities to formulate elaborate explanations (e.g., high-ability students monopolize the formulation of explanations), whereas in medium-low dyads, germane load is higher for medium-ability students because they have to opportunity to explain their reasoning to low-ability students and are thus more actively engaged in the collaborative process (Tudge et al. 1996). This ability or inability to engage in processes that foster germane load may then explain the performance of medium ability students. Combining the analysis of group processes with existing measures of cognitive load to better understand and identify conditions under which collaborative learning is most effective and efficient is a new promising research direction for collaborative learning.

\section{Providing Alternative Measures of Cognitive Load}

Combining cognitive load measures with an analysis of the collaborative process can lead to additional ways of measuring cognitive load. This would mean that researchers examine the collaborative process to look for speech features (e.g., pause length or response latency) and/or linguistic and grammatical cues (e.g., the use of singular versus plural pronouns such as "I" and "we") that could give an indication of the cognitive load learners experience in a collaborative learning environment (see, for example, the work of Khawaja et al. 2009).

The value of such an approach is illustrated by the work of Khawaja et al. $(2009 ; 2007)$. By studying the process of collaboration, they were able to demonstrate that in high-load collaborative conditions, speech, linguistic, and grammatical features were different from low-load conditions. In high-load conditions, Khawaja et al. noted significantly longer speech pauses and significantly less use of singular pronouns (e.g., "I" and "you"), compared with low-load conditions. Their research provides insight into which features of collaborative speech are related to cognitive load and show that aspects of the collaborative process can be used as nonintrusive measures cognitive load. 
Furthermore, by investigating collaborative learning in such a way, it is also possible to study how cognitive load due to transaction costs varies over time. At one point in time, the experienced load due to transaction costs may be low, while at another point, it may be high — or even too high — when it reaches a peak (Paas et al. 2003b). Studying the transaction costs of collaborative learning along with learners' experienced cognitive load may help us address the question whether, for example, the average load during the entire collaborative process affects student learning, or whether student learning is affected by moments during which group members experience a peak load.

\section{Conclusion and Discussion}

The aim of this article was to discuss the possible advantages of studying collaborative learning, using methodologies developed for process-oriented research and cognitive load theory (CLT). We argue that research combining process-oriented research and CLT constitutes a promising, new approach to research on collaborative learning. For example, when these research traditions are combined, it is possible to gain a better understanding of the coordinative and communicative processes that contribute to the transaction costs of collaborative learning. It will provide additional insight to the specific processes that contribute to student learning during collaborative learning (i.e., processes that generate germane cognitive load) and processes that are detrimental for learning (i.e., processes that generate extraneous cognitive load).

Additional issues need to be resolved to pursue this new line of research. One such issue may be the question how to measure cognitive load in collaborative situations. Paas' (1992) nine-point rating scale may, for example, be completed by all group members, which provides us with information about the amount of invested mental effort by each group member. However, when groups of collaborating learners are considered information processing systems (Hinsz et al. 1997; F. Kirschner et al. 2009a, c), an individual measure of cognitive load could be extended with a measure of group cognitive load (i.e., cognitive load experienced by the group as a whole). Future work should address this possibility as well as the possibility to include process-oriented data when determining cognitive load.

The complex interplay between task characteristics, learner characteristics, and group characteristics constitutes another challenge for this new line of research. Consider, for example, the following two dyads consisting of a medium and a high-ability student. The first dyad consists of two students who are unfamiliar with each other, while the second dyad consists of two friends. The dyads are collaborating on a simple recall task. For the first dyad, the extraneous load caused by the need to coordinate their actions may be quite high, thereby negatively affecting the learning process of both partners. On the other hand, because the members of the second dyad have a shared social history, the transfer of information in their dyad may be more efficient and they may require less extensive regulation and coordination of their efforts (Adams et al. 2005; Janssen et al. 2009). In other words, the transaction costs of collaboration impose only a small extraneous load on these two learners, and thus, their learning is not negatively affected by the collaboration (cf., Andersson and Rönnberg 1995). This example shows how group-level factors such as group member familiarity may affect the occurrence of extraneous cognitive load differently for different groups.

To make matters even more complex, within a dyad, the factors that contribute to germane or extraneous cognitive load may also differ between group members. When a medium-ability student, for example, tries to explain his or her reasoning to a high-ability 
student, this may induce germane load on the part of the medium-ability student because the elaboration and reorganization of cognitive schemas stimulated by the explanation are beneficial to his/her learning process (Webb 1991). Simultaneously, this explanation may induce extraneous cognitive load for the high-ability student, because this student is already aware of this information (i.e., it is redundant; see Mayer et al. 2001). These examples demonstrate the complexity of studying collaborative learning. On the other hand, these examples also show why a combination of process-oriented research, and CLT is needed to disentangle the individual- and group-level factors involved in collaborative learning. Only studying the process of collaboration would not give insight into whether the interaction processes are beneficial (i.e., germane load) or deleterious (i.e., extraneous load) for learning. Alternatively, only measuring the level of cognitive load would not give information about the processes that contributed to this load. Both are needed to completely grasp how collaboration and interaction affect student learning. When these measures are combined with data about individual factors (i.e., performance on a pretest to determine cognitive ability) or group factors (i.e., information about the level of familiarity of group members), the complex interplay between individual- and group-level factors can be studied effectively.

A last issue concerns the complexity and extensiveness of studying the process of collaborative learning. The development of a method that can be used to analyze communication protocols can be difficult. A coding system has to be developed based on theoretical motivations and then tested (e.g., with respect to reliability and validity of the system). Additionally, researchers have to pay attention to the reliability and validity of the system (Strijbos et al. 2006). Furthermore, the process of analyzing a great number of protocols can be time consuming (Rosé et al. 2008). These are important challenges that need to be addressed when process-oriented research is combined with CLT, although recent developments to automate the coding of the collaborative process may extensively decrease the time needed to code a large number of protocols (Erkens and Janssen 2008; Rosé et al. 2008).

In spite of these challenges, we feel that the possibility to combine process-oriented research with CLT constitutes a promising, new way of researching collaborative learning. In our own research, we hope to explore this possibility further. In doing so, we hope to gain a better understanding of the factors that contribute to the effectiveness of collaborative learning and to generate effective, efficient, and enjoyable instructional procedures for collaborative learning.

Open Access This article is distributed under the terms of the Creative Commons Attribution Noncommercial License which permits any noncommercial use, distribution, and reproduction in any medium, provided the original author(s) and source are credited.

\section{References}

Adams, S. J., Roch, S. G., \& Ayman, R. (2005). Communication medium and member familiarity: The effects on decision time, accuracy, and satisfaction. Small Group Research, 36, 321-353.

Andersson, J., \& Rönnberg, J. (1995). Recall suffers from collaboration: Joint recall effects of friendship and task complexity. Applied Cognitive Psychology, 9, 199-211.

Artzt, A. F., \& Armour-Thomas, E. (1997). Mathematical problem solving in small groups: Exploring the interplay of students' metacognitive behaviors, perceptions, and ability levels. Journal of Mathematical Behavior, 16, 63-74.

Baddeley, A. D. (1986). Working memory. Oxford: Clarendon Press. 
Barron, B. (2003). When smart groups fail. Journal of the Learning Sciences, 12, 307-359.

Beers, P. J., Boshuizen, H. P. A., Kirschner, P. A., \& Gijselaers, W. H. (2007). The analysis of negotiation of common ground in CSCL. Learning and Instruction, 17, 427-435.

Bernard, R. M., \& Lundgren Cayrol, K. (2001). Computer conferencing: An environment for collaborative project-based learning in distance education. Educational Research and Evaluation, 7, 241-261.

Bossert, S. T. (1988). Cooperative activities in the classroom. In E. Z. Rothkopf (Ed.), Review of Research in Education Vol. 13 (pp. 225-250). Washington, DC: American Educational Research Association (AERA).

Buchs, C., \& Butera, F. (2009). Is a partner's competence threatening during dyadic cooperative work? It depends on resource interdependence. European Journal Of Psychology Of Education, 24, 145154.

Ciborra, C., \& Olson, M. H. (1988). Encountering electronic work groups: A transaction costs perspective. In Proceedings of the 1988 ACM conference on computer-supported collaborative work. OR: Portland.

Cohen, E. G. (1994). Restructuring the classroom: Conditions for productive small groups. Review of Educational Research, 64, 1-35.

Cowan, N. (2010). The magical mystery four: How is working memory capacity limited, and why? Current Directions in Psychological Science, 19, 51-57.

De Jong, F., Kollöffel, B., Van der Meijden, H., Kleine Staarman, J., \& Janssen, J. (2005). Regulative processes in individual, 3D and computer supported cooperative learning contexts. Computers in Human Behavior, 21, 645-670.

Denessen, E., Veenman, S., Dobbelsteen, J., \& Van Schilt, J. (2008). Dyad composition effects on cognitive elaboration and student achievement. Journal of Experimental Education, 76, 363-383.

Dillenbourg, P. (1999). Introduction: what do you mean by "Collaborative Learning"? In P. Dillenbourg (Ed.), Collaborative learning: cognitive and computational approaches (pp. 1-19). Amsterdam: Pergamon.

Dillenbourg, P., Baker, M., Blaye, A., \& O’Malley, C. (1996). The evolution of research on collaborative learning. In H. Spada \& P. Reimann (Eds.), Learning in humans and machine: towards an interdisciplinary learning science (pp. 189-211). Oxford: Elsevier.

Elbers, E., \& Streefland, L. (2000). Collaborative learning and the construction of common knowledge. European Journal of Psychology of Education, 15, 479-490.

Erkens, G., \& Janssen, J. (2008). Automatic coding of online collaboration protocols. International Journal of Computer Supported Collaborative Learning (ijCSCL), 3, 447-470.

Erkens, G., Jaspers, J., Prangsma, M., \& Kanselaar, G. (2005). Coordination processes in computer supported collaborative writing. Computers in Human Behavior, 21, 463-486.

Fawcett, L. M., \& Garton, A. F. (2005). The effect of peer collaboration on children's problem-solving ability. British Journal Of Educational Psychology, 75, 157-169.

Hasler, B. S., Kersten, B., \& Sweller, J. (2007). Learner control, cognitive load and instructional animation. Applied Cognitive Psychology, 21, 713-729.

Hinsz, V. B., Tindale, R. S., \& Vollrath, D. A. (1997). The emerging conceptualization of groups as information processors. Psychological Bulletin, 121, 43-64.

Hogan, K., Nastasi, B. K., \& Pressley, M. (1999). Discourse patterns and collaborative scientific reasoning in peer and teacher-guided discussions. Cognition and Instruction, 17, 379-432.

Janssen, J., Erkens, G., Kanselaar, G., \& Jaspers, J. (2007). Visualization of participation: Does it contribute to successful computer-supported collaborative learning? Computers \& Education, 49, 1037-1065.

Janssen, J., Erkens, G., Kirschner, P. A., \& Kanselaar, G. (2009). Influence of group member familiarity on online collaborative learning. Computers in Human Behavior, 25, 161-170.

Janssen, J., Erkens, G., Kirschner, P. A., \& Kanselaar, G. (2010). Effects of representational guidance during computer-supported collaborative learning. Instructional Science, 38, 59-88.

Johnson, D. W., \& Johnson, R. T. (2009). An educational psychology success story: Social Interdependence theory and cooperative learning. Educational Researcher, 38, 365-379.

Johnson, D. W., Johnson, R. T., \& Stanne, M. B. (1989). Impact of goal and resource interdependence on problem-solving success. The Journal of Social Psychology, 129, 621-629.

Jones, A., \& Issroff, K. (2005). Learning technologies: Affective and social issues in computer-supported collaborative learning. Computers \& Education, 44, 395-408.

Khawaja, M. A., Ruiz, N., \& Chen, F. (2007). Potential speech features for cognitive load measurement. In Proceedings of the 19th Australasian conference on Computer-Human Interaction: Entertaining User Interfaces (pp. 57-60). New York: ACM.

Khawaja, M. A., Chen, F., \& Marcus, N. (2009). Analysis of collaborative speech for grammatical cues of cognitive load. Paper presented at the Third International Cognitive Load Theory Conference, Heerlen, The Netherlands. 
Kirschner, P. A., Sweller, J., \& Clark, R. E. (2006). Why minimal guidance during instruction does not work: An analysis of the failure of constructivist, discovery, problem-based, experiential, and inquiry-based teaching. Educational Psychologist, 41, 75-86.

Kirschner, P. A., Beers, P. J., Boshuizen, H. P. A., \& Gijselaers, W. H. (2008). Coercing shared knowledge in collaborative learning environments. Computers in Human Behavior, 24, 403-420.

Kirschner, F., Paas, F., \& Kirschner, P. A. (2009a). A cognitive load approach to collaborative learning: United brains from complex learning. Educational Psychology Review, 21, 31-42.

Kirschner, F., Paas, F., \& Kirschner, P. A. (2009b). Efficiency of individual versus group learning as a function of task complexity. Manuscript submitted for publication.

Kirschner, F., Paas, F., \& Kirschner, P. A. (2009c). Individual and group-based learning from complex cognitive tasks: Effects on retention and transfer efficiency. Computers in Human Behavior, 25, 306-314.

Klein, J. D., \& Pridemore, D. R. (1992). Effects of cooperative learning and need for affiliation on performance, time on task, and satisfaction. Educational Technology Research and Development, 40, 39-47.

Kreijns, K., Kirschner, P. A., \& Jochems, W. (2003). Identifying the pitfalls for social interaction in computer-supported collaborative learning environments: A review of the research. Computers in Human Behavior, 19, 335-353.

Kuhn, D., \& Udell, W. (2003). The development of argument skills. Child Development, 74, 1245-1260.

Kumpulainen, K., Salovaara, H., \& Mutanen, M. (2001). The nature of students' sociocognitive activity in handling and processing multimedia-based science material in a small group learning task. Instructional Science, 29, 481-515.

Langfred, C. W. (2000). Work-group design and autonomy: A field study of the interaction between task interdependence and group autonomy. Small Group Research, 31, 54-70.

Laughlin, P. R., Bonner, B. L., \& Miner, A. G. (2002). Groups perform better than the best individuals on Letters-to-Numbers problems. Organizational Behavior and Human Decision Processes, 88, 605-620.

Laughlin, P. R., Hatch, E. C., Silver, J. S., \& Boh, L. (2006). Groups perform better than the best individuals on letters-to-numbers problems: Effects of group size. Journal Of Personality and Social Psychology, 90, 644-651.

Leitão, S. (2000). The potential of argument in knowledge building. Human Development, 43, 332-360.

Lou, Y., Abrami, P. C., \& d'Apollonia, S. (2001). Small group and individual learning with technology: A meta-analysis. Review of Educational Research, 71, 449-521.

Marcus, N., Cooper, M., \& Sweller, J. (1996). Understanding instructions. Journal of Education \& Psychology, 88, 49-63.

Mayer, R. E., Heiser, J., \& Lonn, S. (2001). Cognitive constraints on multimedia learning: When presenting more material results in less understanding. Journal of Education \& Psychology, 93, 187-198.

Mercer, N. (1996). The quality of talk in children's collaborative activity in the classroom. Learning and Instruction, 6, 359-377.

Meudell, P. R., Hitch, G. J., \& Kirby, P. (1992). Are two heads better than one: Experimental investigations of the social facilitation of memory. Applied Cognitive Psychology, 6, 525-543.

Mevarech, Z. R., \& Kramarski, B. (2003). The effects of metacognitive training versus worked-out examples on students' mathematical reasoning. The British Journal of Educational Psychology, 73, 449-471.

Miller, G. (1956). The magical number seven, plus or minus two: Some limits on our capacity for processing information. Psychological Review, 63, 81-97.

Munneke, L., Andriessen, J., Kanselaar, G., \& Kirschner, P. (2007). Supporting interactive argumentation: Influence of representational tools on discussing a wicked problem. Computers in Human Behavior, 23, 1072-1088.

Nichols, J. D. (1996). The effects of cooperative learning on student achievement and motivation in a high school geometry class. Contemporary Educational Psychology, 21, 467-476.

O’Donnell, A. M., \& O'Kelly, J. (1994). Learning from peers: Beyond the rhetoric of positive results. Educational Psychology Review, 6, 321-349.

Ortiz, A. E., Johnson, D. W., \& Johnson, R. T. (1996). The effect of positive goal and resource interdependence on individual performance. The Journal of Social Psychology, 136, 243-249.

Paas, F. (1992). Training strategies for attaining transfer of problem-solving skill in statistics: A cognitive load approach. Journal of Education \& Psychology, 84, 429-434.

Paas, F., \& Van Merriënboer, J. J. G. (1993). The efficiency of instructional conditions: An approach to combine mental effort and performance measures. Human Factors, 35, 737-743.

Paas, F., \& Van Merriënboer, J. J. G. (1994). Instructional control of cognitive load in the training of complex cognitive tasks. Educational Psychology Review, 6, 351-371.

Paas, F., Renkl, A., \& Sweller, J. (2003). Cognitive load theory and instructional design: Recent developments. Educational Psychologist, 38, 1-4. 
Paas, F., Tuovinen, J. E., Tabbers, H., \& Van Gerven, P. W. M. (2003). Cognitive load measurement as a means to advance cognitive load theory. Educational Psychologist, 38, 63-71.

Paas, F., Renkl, A., \& Sweller, J. (2004). Cognitive load theory: Instructional implications of the interaction between information structures and cognitive architecture. Instructional Science, 32, 1-8.

Paulus, T. M. (2005). Collaboration or cooperation? Analyzing small group interactions in educational environments. In T. S. Roberts (Ed.), Computer-supported collaborative learning in higher education (pp. 100-124). Hershey, PA: Idea Group Publishing.

Pelled, L. H., Eisenhardt, K. M., \& Xin, K. R. (1999). Exploring the black box: An analysis of work group diversity, conflict, and performance. Administrative Science Quarterly, 44, 1-28.

Phielix, C., Prins, F. J., \& Kirschner, P. A. (2010). Awareness of group performance in a CSCL-environment: Effects of peer feedback and reflection. Computers in Human Behavior, 26, 151-161.

Roschelle, J., \& Teasley, S. (1995). The construction of shared knowledge in collaborative problem solving. In C. O’Malley (Ed.), Computer-supported collaborative learning (pp. 69-97). New York: Springer-Verlag.

Rosé, C. P., Wang, Y.-C., Cui, Y., Arguello, J., Weinberger, A., Stegmann, K., et al. (2008). Analyzing collaborative learning processes automatically: Exploiting the advances of computational linguistics in computer-supported collaborative learning. International Journal of Computer Supported Collaborative Learning, 3, 237-271.

Roseth, C. J., Johnson, D. W., \& Johnson, R. T. (2008). Promoting early adolescents' achievement and peer relationships: The effects of cooperative, competitive, and individualistic goal structures. Psychological Bulletin, 134, 223-246.

Salas, E., Sims, D. E., \& Burke, C. S. (2005). Is there a "big five" in teamwork? Small Group Research, 36, 555-599.

Salomon, G., \& Globerson, T. (1989). When teams do not function the way they ought to. International Journal of Educational Research, 13, 89-99.

Savery, J. R., \& Duffy, T. M. (1995). Problem based learning: An instructional model and its constructivistic framework. Educational Technology, 35, 31-38.

Slavin, R. E. (1980). Cooperative Learning. Review of Educational Research, 50, 315-342.

Slavin, R. E. (1996). Research on cooperative learning and achievement: What we know, what we need to know. Contemporary Educational Psychology, 21, 43-69.

Slof, B., Erkens, G., Kirschner, P. A., \& Jaspers, J. G. M. (in press). Design and effects of a representational scripting tool on group performance. Educational Technology Research and Development.

Springer, L., Donovan, S. S., \& Stanne, M. E. (1999). Effects of small-group learning on undergraduates in science, mathematics, engineering, and technology: A meta-analysis. Review of Educational Research, 69, 21-51.

Stodolsky, S. S. (1984). Frameworks for studying instructional processes in peer work-groups. In P. L. Peterson, L. C. Wilkinson, \& M. Hallinan (Eds.), The social context of instruction: Group organization and group processes (pp. 107-124). Orlando, FL: Academic Press.

Strijbos, J. W., Martens, R. L., Prins, F. J., \& Jochems, W. M. G. (2006). Content analysis: What are they talking about? Computers \& Education, 46, 29-48.

Sweller, J. (2004). Instructional design consequences of an analogy between evolution by natural selection and human cognitive architecture. Instructional Science, 32, 9-31.

Sweller, J. (2010, this issue). Element interactivity and intrinsic, extraneous and germane cognitive load. Educational Psychology Review.

Sweller, J., \& Sweller, S. (2006). Natural information processing systems. Evolutionary Pscyhology, 4, 434-458.

Sweller, J., Van Merriënboer, J. J. G., \& Paas, F. (1998). Cognitive architecture and instructional design. Educational Psychology Review, 10, 251-296.

Teasley, S. D., \& Roschelle, J. (1993). Constructing a joint problem space: The computer as a tool for sharing knowledge. In S. P. Lajoie (Ed.), Computers as cognitive tools: Technology in education (pp. 229-258). Hillsdale, NJ: Lawrence Erlbaum Associates, Inc.

Tindale, R. S., \& Kameda, T. (2000). Social sharedness as a unifying theme for information processing in groups. Group Processes and Intergroup Relations, 3, 123-140.

Tindale, R. S., \& Sheffey, S. (2002). Shared information, cognitive load and group memory. Group Processes and Intergroup Relations, 5, 5-18.

Tudge, J. R. H. (1989). When collaboration leads to regression: Some negative consequences of sociocognitive conflict. European Journal of Social Psychology, 19(2), 123-138.

Tudge, J. R. H., Winterhoff, P. A., \& Hogan, D. M. (1996). The cognitive consequences of collaborative problem solving with and without feedback. Child Development, 67(6), 2892-2909.

Tuovinen, J. E., \& Paas, F. (2004). Exploring multidimensional approaches to the efficiency of instructional conditions. Instructional Science, 32, 133-152.

Van Boxtel, C., Van der Linden, J., \& Kanselaar, G. (2000). Collaborative learning tasks and the elaboration of conceptual knowledge. Learning and Instruction, 10, 311-330. 
Van der Linden, J. L., Erkens, G., Schmidt, H., \& Renshaw, P. (2000). Collaborative learning. In P. R. J. Simons, J. L. Van der Linden, \& T. Duffy (Eds.), New learning (pp. 1-19). Dordrecht: Kluwer Academic Publishers.

Van der Meijden, H., \& Veenman, S. (2005). Face-to-face versus computer-mediated communication in a primary school setting. Computers in Human Behavior, 21, 831-859.

Van Gerven, P. W. M., Paas, F., Van Merriënboer, J. J. G., \& Schmidt, H. G. (2002). Cognitive load theory and aging: Effects of worked examples on training efficiency. Learning and Instruction, 12, 87-105.

Van Gog, T., \& Paas, F. (2008). Instructional efficiency: Revisiting the original construct in educational research. Educational Psychologist, 43, 16-26.

Van Gog, T., Kester, L., Nievelstein, F., Giesbers, B., \& Paas, F. (2009). Uncovering cognitive processes: Different techniques that can contribute to cognitive load research and instruction. Computers in Human Behavior, 25, 325-331.

Van Gog, T., Paas, F., Marcus, N., Ayres, P., \& Sweller, J. (2009). The mirror neuron system and observational learning: Implications for the effectiveness of dynamic visualizations. Educational Psychology Review, 21, 21-30.

Van Merriënboer, J. J. G., \& Sweller, J. (2005). Cognitive load theory and complex learning: Recent developments and future directions. Educational Psychology Review, 17, 147-177.

Vygotsky, L. S. (1978). Mind in Society. The Development of Higher Psychological Processes. Cambridge, MA: Harvard University Press.

Webb, N. M. (1989). Peer interaction and learning in small groups. International Journal of Educational Research, 13(1), 21-39.

Webb, N. M. (1991). Task-related verbal interaction and mathematics learning in small groups. Journal for Research in Mathematics Education, 22(5), 366-389.

Webb, N. M., \& Palincsar, A. S. (1996). Group processes in the classroom. In D. C. Berliner (Ed.), Handbook of educational psychology (pp. 841-873). New York: Simon \& Schuster Macmillan.

Webb, N. M., \& Farivar, S. (1999). Developing productive group interaction in middle school mathematics. In A. O’Donnell \& A. King (Eds.), Cognitive perspectives on peer learning (pp. 117-149). Mahwah, NJ: Lawrence Erlbaum Associates, Publishers.

Webb, N. M., \& Mastergeorge, A. (2003). Promoting effective helping behavior in peer-directed groups. International Journal of Educational Research, 39, 73.

Webb, N. M., Troper, J. D., \& Fall, R. (1995). Constructive activity and learning in collaborative small groups. Journal of Education \& Psychology, 87, 406-423.

Webb, N. M., Nemer, K. M., Chizhik, A. W., \& Sugrue, B. (1998). Equity issues in collaborative group assessment: Group composition and performance. American Educational Research Journal, 35(4), 607-651.

Webb, N. M., Nemer, K. M., \& Zuniga, S. (2002). Short circuits or superconductors? Effects of group composition on high-achieving students' science assessment performance. American Educational Research Journal, 39, 943-989.

Wegner, D. M. (1987). Transactive memory: A contemporary analysis of the group mind. In B. Mullen \& G. R. Goethals (Eds.), Theories of group behavior (pp. 185-208). New York: Springer-Verlag.

Wegner, D. M. (1995). A computer network model of human transactive memory. Social Cognition, 13, 319-339.

Weldon, M. S., \& Bellinger, K. D. (1997). Collective memory: Collaborative and individual processes in remembering. Journal of Experimental Psychology. Learning, Memory, and Cognition, 23, 1160-1175.

Yackel, E., Cobb, P., \& Wood, T. (1991). Small-group interactions as a source of learning opportunities in second-grade mathematics. Journal for Research in Mathematics Education, 22, 390-408.

Yamane, D. (1996). Collaboration and its discontents: Steps toward overcoming barriers to successful group projects. Teaching Sociology, 24, 378-383. 